\title{
PENDAMPINGAN PENINGKATAN KETERAMPILAN MENGAJAR MOTORIK HALUS MELALUI KERTAS KOKORU BAGI GUGUS IGTKI DAN HIMPAUDI KECAMATAN SUNGAI KUNJANG SAMARINDA
}

\author{
Fachrul Rozie $1^{*}$ \\ Wiwik Haryani² \\ 1,2 PGPAUD, Universitas Mulawarman, Samarinda, Indonesia \\ fachrul.rozie@fkip.unmul.ac.id ${ }^{1^{*}}$ ) \\ wiwik.haryani@fkip.unmul.ac.id ${ }^{2)}$
}

\author{
Kata Kunci: [Guru \\ PAUD, Kertas kokoru; \\ Keterampilan mengajar]
}

\begin{abstract}
Abstrak: Kegiatan ini dilatarbelakangi perlunya peningkatan keterampilan mengajar guru dalam aktivitas belajar motorik halus terutama jenjang usia 4-6 tahun. Pemilihan bahan kertas kokoru sebagai sumber belajar alternatif yang memiliki daya visual yang menarik serta tingkat kesulitan untuk pembelajaran menggunting, menempel dan melipat. Tujuan kegiatan pengabdian masyarakat dilakukan agar guru PAUD memiliki wawasan baru untuk memanfaatkan kertas kokoru sebagai bahan materi pembelajaran di kelas. Metode yang dilaksanakan yakni simulasi pembelajaran berbasis motorik halus melalui berbagai kegiatan seperti: (1) Menjahit; (2) Montase; (3) Kolase; (4) Mozaik; (5) Melukis; dan (6) Menggunakan bahan kertas kokoru. Sehingga sangat tepat sasaran bagi guru - guru PAUD dalam kegiatan program pengabdian ini untuk memperkaya wawasan dan pengalaman baru terutama bagi guru pemula. Kegiatan dilaksanakan di salah satu gugus kecamatan Sungai Kunjang, Kota Samarinda sejumlah 25 peserta selama dua hari. Peserta mendapat tugas secara kelompok untuk memperoleh hasil kemampuan yang diharapkan dalam pembelajaran motorik halus. Dengan demikian, keterampilan mengajar untuk guru PAUD dalam pembelajaran motorik halus bagi anak usia 4-6 tahun dapat dilakukan dengan memanfaatkan material kertas kokoru di berbagai aktivitas.
\end{abstract}

\section{Pendahuluan}

Pendidikan anak usia dini pada dasarnya meliputi seluruh upaya dan tindakan yang di lakukan oleh pendidik dan orang tua dalam proses perawatan, pengasuhan dan pendidikan pada anak dengan menciptakan lingkungan dimana anak dapat mengeksplorasi pengalaman belajar yang diperolehnya dengan cara mengamati, meniru, bereksperimen yang berlangsung secara berulang - ulang dan melibatkan seluruh potensi dan kecerdasan anak. Beberapa hasil penelitian menunjukan bahwa pendidikan anak usia dini merupakan masa yang sangat penting. Sebagaimana kajian penelitian Arif \& Maulana (2019) melaporkan bahwa pengembangan pembelajaran motorik halus anak usia dini melalui aktivitas bermain melibatkan gerakan fisik sebagai bentuk stimulasi dukungan 
kesiapan anak bersekolah selanjutnya. Sementara, hasil penelitian Eviani menggambarkan penerapan bermain meronce dengan media manik-manik pada anak usia dini dapat dilakukan untuk pembelajaran motorik halus yang menitikberatkan pada guru sebagai fasilitator menyediakan berbagai bentuk manik-manik dengan warna yang menarik (2020). Dengan kata lain, dapat dipahami bahwa anak usia dini merupakan sosok individu yang sedang menjalani proses perkembangan dengan pesat dan fundamental. Sehingga pada mana masa tersebut membutuhkan stimulasi yang diberikan oleh lingkungan sekitar terutama sekolah.

Namun, kajian empiris lain menjadi pembanding pada berbagai media pembelajaran motorik halus. Sebagaimana hasil penelitian dari Dewi \& Fauziyah (2019) menekankan pemanfaatan kertas kokoru dapat sebagai alternatif pembelajaran $3 \mathrm{M}$ (menggunting, menempel, dan menggulung) di kelas-kelas PAUD terutama usia prasekolah. Hasil penelitian tersebut merupakan hasil skripsi yang dibimbing oleh tim pengabdian masyarakat untuk mengembangkan khazanah keilmuan pedagogik guru PAUD pemula pada pembelajaran motorik halus terutama dimensi keterampilan mengajar.

Sehingga, ide pengabdian masyarakat ini mengadopsi hasil penelitian tersebut untuk membantu guru PAUD Pemula dalam meningkatkan kemampuan keterampilan mengajar terutama di kecamatan Sungai Kunjag, Samarinda. Program pengabdian masyarakat tersebut dilakukan dalam bentuk workshop selama dua hari yang diikuti oleh 25 peserta yang telah diseleksi. Pemilihan kecamatan sungai kunjang, karena kecamatan tersebut merupakan kawasan yang banyak berdiri lembaga-lembaga PAUD baik yang sudah lama atau baru berdiri. Keadaan demografis pun wilayah tersebut termasuk dalam pinggiran kota Samarinda.

Berdasarkan hasil studi literatur di atas, fenomena guru-guru yang belum S1 PGPAUD atau tidak linier banyak yang mengambil program kuliah di salah satu kampus negeri yaitu Universitas Terbuka. Sebagian guru-guru tersebut merupakan guru PAUD pemula yang membutuhkan kesempatan untuk mengenal pembelajaran PAUD secara mendalam Hal tersebut sebagai deskripsi analisis situasi yang menggambarkan belum adanya pengembangan motorik halus secara berkelanjutan. Hasil pengamatan dan interaksi tim, kebanyakan guru-guru PAUD pemula belum memahami aspek perkembangan motorik halus merupakan kemampuan dasar agar anak memiliki keterampilan hidup (life skill) dalam mengatasi permasalahan sendiri. Melalui motorik halus juga, seharusnya anak mampu mengkreasikan ide dari imajinasi mereka pada sebuah karya. Oleh sebab itu, perlu adanya pengetahuan baru yang dapat diberikan kepada guru-guru tentang kegiatan melalui kertas kokoru. Kertas kokoru merupakan variasi media yang untuk mengembangkan kreativitas anak dalam proses pembelajaran karena kertas kokoru bisa dibentuk menjadi sesuai dengan imajinasi dan yang disenangi anak. Meskipun perlu adanya peran guru dalam memberikan bimbingan dan demonstrasi menggunakan kertas kokoru secara tepat. Dengan demikian, tujuan dan manfaat program pengabdian masyarakat ini sebagai upaya memberikan pengetahuan baru konsep kertas kokoru bagi guru PAUD yang belum S1 PAUD/ lulusan SMA bahwa kertas kokoru dapat digunakan sebagai bahan kegiatan pembelajaran motorik halus. 


\section{Metode Pelaksanaan}

\section{Tempat dan waktu pelaksanaan}

Kegiatan pengabdian masyarakat ini dilaksanakan di TK Jamiyyatul Muta'allimin yang merupakan bagian dari anggota gugus IGTKI Kecamatan Sungai Kunjang, Samarinda. Adapun waktu pelaksanaan dilakukan selama dua hari secara berturut-turut dari pukul 08.00 - 15.00 WITA. Tahapan kegiatan dilakukan melalui kegiatan survey di 16 sekolah yang memiliki guru PAUD pemula. Guru PAUD pemula yang telah dipilih akan mengisi formulir kesediaan sebagai peserta kegiatan pengabdian masyarakat. Kegiatan pengabdian dilaksanakan pada tanggal 2-3 Mei 2018.

\section{Sasaran/ Mitra}

Khalayak sasaran kegiatan pengabdian kepada masyarakat ini adalah guru PAUD Pemula di lingkungan kecamatan Sungai Kunjang. Dalam kegiatan pengabdian kepada masyarakat ini seluruh guru, yaitu sejumlah 25 orang dilibatkan sebagai partisipan pengabdian masyarakat.

\section{Metode Pengabdian}

Metode pengabdian dilakukan melalui workshop yang difasilitasi oleh tim (Dosen) dan fasilitator mahasiswa semester VI yang direkrut dengan tujuan membantu demonstrasi pemanfaatan bahan kertas kokoru dalam pembelajaran motorik halus. Mahasiswa tersebut telah menyelesaikan matakuliah pengembangan alat permainan edukatif (APE) sebagai matakuliah wajib di program studi. Partisipan yang hadir dibentuk kelompok sesuai wilayah lokasi Lembaga yang terbentuk menjadi 5 kelompok. Hal tersebut bertujuan untuk saling menjadi teman sejawat dalam kegiatan berlangsung. Pendampingan dilakukan secara berkelanjutan selama dua hari kegiatan dengan indikator keberhasilan partisipan dapat menunjukkan hasil keterampilan mengajar menggunakan bahan kertas kokoru dalam pembelajaran motorik halus.

\section{Indikator Keberhasilan \& Metode Evaluasi}

Kegiatan pengabdian masyarakat ini mengacu pada indikator keberhasilan partisipan mampu menunjukkan hasil keterampilan mengajar menggunakan bahan kertas kokoru dalam pembelajaran motorik halus selama dua hari. Hal tersebut dilakukan evaluasi pada setiap kegiatan dengan melakukan pengamatan secara langsung dan dokumentasi kegiatan. Parameter keberhasilan tersebut dapat diketahui pada adanya perubahan persepsi partisipan terhadap pemanfaatan kertas kokoru di hari pertama dan berani melakukan presentasi hasil karya kelompok di hari kedua.

\section{Hasil dan Pembahasan}

\section{Karakteristik Partisipan Kegiatan Pengabdian Kepada Masyarakat}

Kegiatan pengabdian masyarakat ini memfokuskan pada guru PAUD pemula di lingkungan gugus IGTKI Kecamatan Sungai Kunjang terutama keterampilan mengajar pembelajaran motorik halus melalui kertas kokoru sebagai mitra. Partisipan yang dipilih ini melalui hasil survey ke lokasi TK yang berada di kecamatan Sungai Kunjang. Tabel berikut menyajikan data karakteristik dari usia, latar belakang pendidikan dan lama mengajar. 
Tabel 1. Karakteristik Partisipan Kegiatan Pengabdian Kepada Masyarakat

\begin{tabular}{|c|c|c|c|c|}
\hline No & Nama & Usia & Latar Belakang Pendidikan & Lama Mengajar \\
\hline 1. & AN & 22 tahun & SMA & 3 tahun \\
\hline 2. & BS & 32 tahun & SMA & 6 tahun \\
\hline 3. & SA & 38 tahun & SMA & 8 tahun \\
\hline 4. & ZE & 45 tahun & SMA & 11 tahun \\
\hline 5. & DV & 25 tahun & SMA & 3 tahun \\
\hline 6. & GN & 27 tahun & SMA & 3 tahun \\
\hline 7. & AR & 21 tahun & SMA & 2 tahun \\
\hline 8. & $\mathrm{AZ}$ & 28 tahun & S1 PAUD & 5 tahun \\
\hline 9. & MR & 28 tahun & S1 PAUD & 5 tahun \\
\hline 10. & FR & 27 tahun & S1 PAUD & 3 tahun \\
\hline 11. & AY & 30 tahun & S1 PAUD & 6 tahun \\
\hline 12. & WK & 35 tahun & S1 PAUD & 5 tahun \\
\hline 13. & HR & 26 tahun & S1 Pendidikan Non PAUD & 4 tahun \\
\hline 14. & BR & 29 tahun & S1 Pendidikan Non PAUD & 5 tahun \\
\hline 15. & RS & 28 tahun & S1 Pendidikan Non PAUD & 5 tahun \\
\hline 16. & ER & 34 tahun & S1 Pendidikan Non PAUD & 5 tahun \\
\hline 17. & $\mathrm{AE}$ & 42 tahun & S1 Pendidikan Non PAUD & 3 tahun \\
\hline 18. & $\mathrm{CH}$ & 40 tahun & S1 Pendidikan Non PAUD & 3 tahun \\
\hline 19. & ST & 33 tahun & S1 Pendidikan Non PAUD & 5 tahun \\
\hline 20. & IL & 25 tahun & S1 Pendidikan Non PAUD & 2 tahun \\
\hline 21. & PO & 29 tahun & S1 Komputer & 3 tahun \\
\hline 22. & EW & 28 tahun & S1 Ekonomi & 1 tahun \\
\hline 23. & MN & 27 tahun & S1 Pertanian & 1 tahun \\
\hline 24. & RA & 30 tahun & S1 Komputer & 2 tahun \\
\hline 25. & MZ & 31 tahun & S1 Psikologi & 2 tahun \\
\hline
\end{tabular}

Data pada Tabel 1 menunjukkan bahwa sebagian besar partisipan berusia $\geq 30$ tahun. Adapun latar belakang pendidikan guru PAUD ternyata banyak yang bukan berasal dari S1 PAUD. Lama mengajar partisipan variasi dari satu tahun hingga 11 tahun. Hal tersebut dipengaruhi oleh banyak partisipan yang kehilangan pekerjaan tetap dan memilih sebagai guru PAUD karena memiliki waktu luang untuk mencari pekerjaan tambahan. Hal ini menunjukkan perlunya pelatihan untuk meningkatkan kompetensi mengajar terutama kepada para guru yang latar belakang pendidikannya bukan PAUD serta memberikan pengetahuan kreasi pemanfaatan kertas kokoru untuk pembelajaran motorik halus (Nurjanah et al., 2019).

\section{Persepsi Kertas Kokoru Sebagai Bahan Material Pembelajaran Motorik Halus pada Anak Usia Dini}

Partisipan dalam mengikuti kegiatan pengabdian kepada masyrakat selama dua hari memberikan pengalaman berbeda antar satu sama lain. Gambaran pengalaman beberapa partisipan yang dilakukan wawancara mendalam setelah kegiatan dapat diketahui dalam manuskrip hasil wawancara di bawah ini.

"Saya mengira selama ini kertas kokoru hanya digunakan untuk pembelajaran siswa SD terutama pada matapelajaran prakarya. Karena menurut saya agak susah diaplikasikan di Pendidikan anak usia dini" (Catatan Wawancara AY, 2 Mei 2018). 
“Tingkat kesulitan untuk menggunakan kertas kokoru ini menurut saya ada pada kegiatan menggulung. Karena motorik halus anak usia 4-5 tahun tidak bisa optimal. Mereka kebanyakan sering kegiatan menggunting dan menempel sesuai pola" (Catatan Wawancara MR, 2 Mei 2018).

Berdasarkan dua hasil wawancara di atas, tim melakukan wawancara pada hari pertama kepada partisipan AY dan MR yang berlatar belakang lulusan S1 PAUD untuk mengetahui persepsi penggunaan kertas kokoru dalam pembelajaran motorik halus. Kedua partisipan tersebut memberikan argumentansi bahwa kertas kokoru kesulitan untuk anak usia 4-5 tahun karena koordinasi mata dan kemampuan tangan belum maksimal Hal ini merupakan gambaran persepsi partisipan yang peneliti simpulkan bahwa stimulasi kegiatan belajar motorik halus menggunakan bahan kertas kokoru tidak hanya dilakukan di lingkungan sekolah, namun lingkungan rumah juga perlu mendukung terutama dalam program holistik integrative (Maulidya Ulfah, 2020).

Adapun beberapa dokumentasi berikut mendeskripsikan hasil kegiatan pengabdian kepada masyarakat untuk guru PAUD pemula dalam meningkatkan keterampilan mengajar melalui motorik halus.

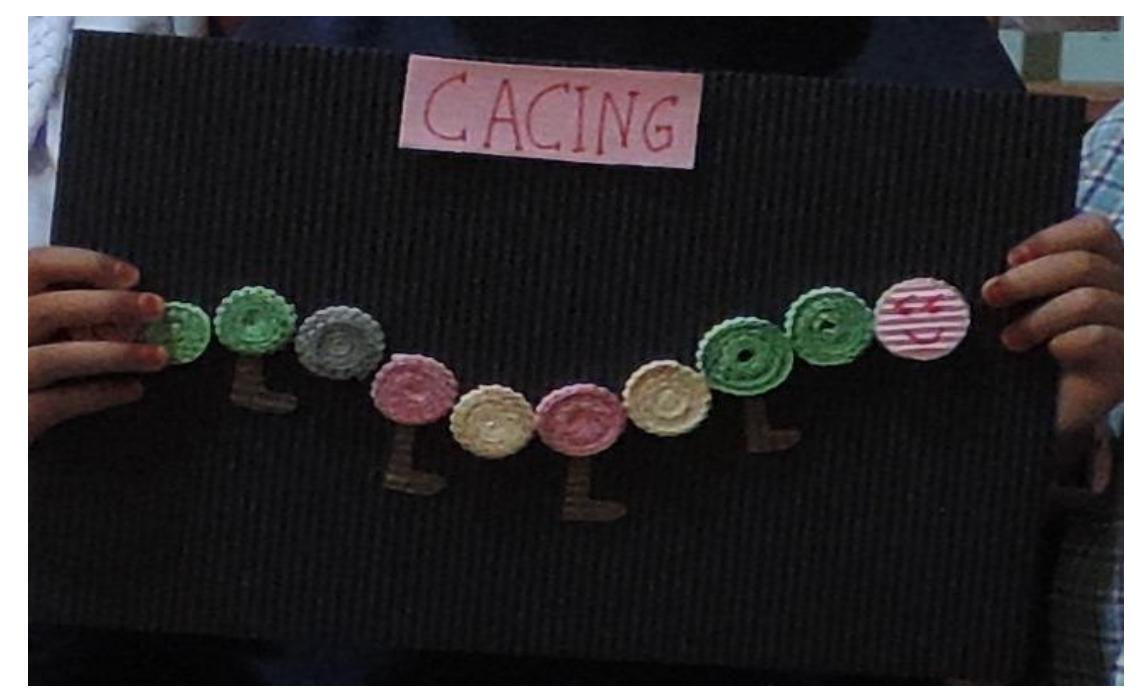

Gambar 1. Salah satu hasil karya partisipan (kegiatan hari pertama)

Gambar 1 memberikan deskripsi bahwa hasil karya dari kertas kokoru sangat sulit dilakukan oleh anak usia 4-6 tahun dalam aktivitas belajar mandiri. Perlu dilakukan bimbingan dan panduan yang anak mudah mengerti melalui guru. Hal tersebut bertujuan untuk menumbuhkan kreativitas anak dalam membuat kreasi sesuai imajinasi melalui pemanfaatan kertas kokoru dalam setiap kegiatan belajar yang berkaitan dengan hasil karya dan cipta karsa (Potensia, 2019). Dengan kata lain, hasil pengabdian kepada masyarakat dapat memberikan wawasan pengetahuan bagi guru PAUD pemula untuk mempelajari berbagai kreasi pemanfaatan kertas kokoru agar mampu menciptakan pembelajaran bermakna bagi anak usia dini. 


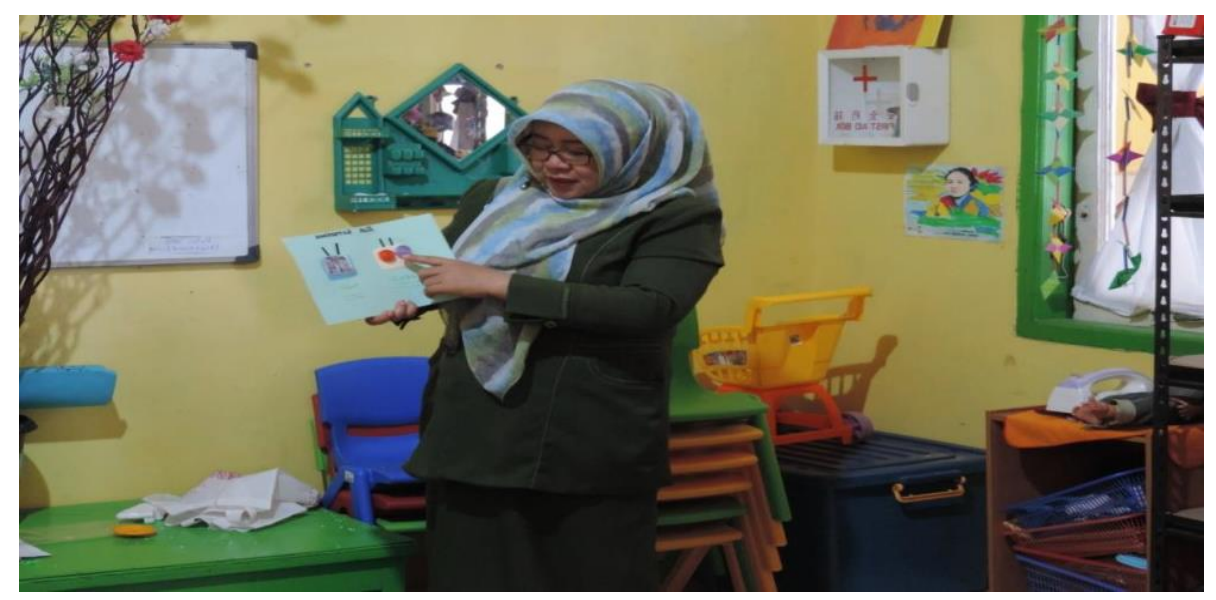

Gambar 2. Salah satu partisipan mempresentasikan hasil karya dalam simulasi pembelajaran di kelas (kegiatan hari kedua)

Partisipan bernama DV dalam dokumentasi di atas merupakan peserta berlatar belakang SMA dengan pengalaman lama mengajar tiga tahun. Ia melakukan simulasi pembelajaran motorik halus dengan membuat LKPD (Lembar Kerja Peserta Didik) dengan kegiatan menggunting dan menempel. Ia berpendapat bahwa hasil simulasi bermain kertas kokoru sangat menantang bagi anak usia 5-6 tahun. Akan tetapi, kreatifitas guru sangat menjadi faktor keberhasilan dalam pembelajaran yang dilakukan.

Dengan kata lain, simulasi pembelajaran motorik halus menggunakan kertas kokoru sangat relevan untuk anak usia dini terutama usia prasekolah. Keberhasilan kegiatan pengabdian kepada masyarakat ini didukung oleh hasil penelitian dari Syahril (2018) yang menyimpulkan penggunaan kertas kokoru dapat dilakukan pada anak usia 4-5 tahun dengan menggunakan beberapa indikator seperti 1) Keaktifan anak dalam melakukan kegiatan, 2) mengkoordinasikan mata dan tangan dalam kegiatan menggulung kertas kokoru, 3) Kerapian anak dalam menggulung kertas kokoru dan 4). Melakukan Gerakan manipulatif untuk menghasilkan bentuk dari media kertas kokoru. Oleh sebab itu hasil pengabdian kepada masyarakat ini dapat memberikan kontribusi untuk guru PAUD pemula dalam melakukan pengembangan kompetensi pedagogik secara berkelanjutan di lingkungan kerja.

\section{Kesimpulan}

Hasil pengabdian kepada masyarakat ini telah memberikan gambaran kertas kokoru dapat menjadi bahan ajar untuk pembelajaran motorik halus pada anak usia 4-6 tahun. Sehingga guru PAUD pemula dapat melakukan variasi media pembelajaran yang relevan dalam kegiatan bermain motorik halus. Berdasarkan hasil pengabdian kepada masyarakat tersebut, disarankan penerapan pembelajaran motorik halus menggunakan kertas kokoru perlu ada pendampingan dan bimbingan yang bersifat holistik antar orangtua dan guru PAUD untuk menumbuhkembangkan kreativitas anak. Hal tersebut dilakukan karena kesulitan anak menggunakan kertas kokoru pada koordinasi mata dan tangan melalui kegiatan menggulung.

\section{Ucapan Terimakasih}

Terimakasih sebesarnya kepada pihak Dekan FKIP Universitas Mulawarman dan Wakil Dekan Akademik yang telah memberikan kesempatan kepada penulis untuk 
melakukan pengabdian kepada masyrakat (PKM) melalui program Hibah FKIP Anggaran BOPTN Tahun 2018 melalui seleksi proposal pengajuan PKM.

\section{Referensi}

Arief Darmawan, \& Amir Maulana. (2019). Pengembangan Model Pembelajaran Permainan Motorik Halus Untuk Anak Usia Dini. Jurnal Kejaora (Kesehatan Jasmani Dan Olahraga), 4(2). https://doi.org/10.36526/kejaora.v4i2.721

Evivani, M. (2020). PERMAINAN FINGER PAINTING UNTUK PENGEMBANGAN KEMAMPUAN MOTORIK HALUS ANAK USIA DINI. Jurnal Warna : Pendidikan Dan Pembelajaran Anak Usia Dini, 5(1). https://doi.org/10.24903/jw.v5i1.427

Hendraningrat, D., \& Fauziah, P. Y. (2019). IMPLEMENTASI KEGIATAN MENGGULUNG, MENGGUNTING, MENEMPEL (3M) ANAK USIA 5-6 TAHUN MELALUI KEGIATAN BERMAIN KERTAS KOKORU PADA KELOMPOK B1 DI PAUD SEROJA IMAN SAMARINDA. Cakrawala Dini: Jurnal Pendidikan Anak Usia Dini, 10(2). https://doi.org/10.17509/cd.v10i2.17381

Maulidya Ulfah. (2020). Pendekatan Holistik Integratif Berbasis Penguatan Keluarga pada Pendidikan Anak Usia Dini Full Day. Jurnal Obsesi : Jurnal Pendidikan Anak Usia Dini,.

Nurjanah, D. S., Setiasih, O., \& Kurniawati, L. (2019). Kemampuan Guru Paud Dalam Menata Lingkungkungan Belajar Ditinjau Dari Kualifikasi Akademik. Edukid, 16(1). https://doi.org/10.17509/edukid.v16i1.20723

Potensia, J. I. (2019). pengaruh kreasi kertas kokoru terhadap perkembangan kreativitas anak di taman kanak nurul yakin ringan-ringan kabupaten padang pariaman. Jurnal Iimiah Potensi, 4(2).

Syahril, N.-. (2018). Peningkatan Motorik Halus Dengan Media Kertas Kokoru Pada Anak Kelompok A Tk Abadi Pertiwi Marangkayu Kabupaten Kutai Kartanegara Tahun Ajaran 2017/2018. Jurnal Warna: Pendidikan Dan Pembelajaran Anak Usia Dini, 2(1). https://doi.org/10.24903/jw.v2i1.189. 